\title{
Correlation Between Awareness of Blended Learning Techniques and Participation Rate in E-Learning: A Case Study
}

\author{
http://dx.doi.org/ijac.v4i3.1738 \\ Nikolaos Antoniadis and Dimitrios Konetas \\ TEI of Epirus, Arta, Greece
}

\begin{abstract}
The use of information and communication technologies both in higher education and in business environments has been dramatically increasing in the past two decades. Blended learning (either synchronous or asynchronous) has been gaining ground and becoming a major alternative to standard teaching. In Greece, higher education institutions provide a substantial part of their curricula in electronic form and instructors are urged to use the elearning tools more. However, students are not always willing to explore and take full advantage of the enhanced possibilities and often are not involved at all. Various modules of on-line education attract students in different ways, thus leading to a natural tendency to use different tools to fulfill their needs. This study aims at exploring the correlation between students' awareness for this learning model, their level of participation in such learning formats and their final performance. Comparative results for participation and performance are presented for a variety of relevant interactive tools employed by the Learning Management System (LMS) of TEI of Epirus, a higher education institution in Greece.
\end{abstract}

Index Terms-Online Learning, Awareness, Cooperation, Higher Education

\section{INTRODUCTION}

The higher education system in Greece comprises two different complementing sections: the University sector and the Technological sector, which includes the Technological Educational Institutions (TEI). The higher education is offered exclusively by the state government, under a specific provision of the Constitution of Greece.

The system has undergone major changes during the past 15 years. The technological sector has been upgraded in order to become a part of the higher education system, whereas the total number of places offered to first-year entrants has dramatically increased from about 20000 to nearly 90000 . Currently, the number of places is only slightly lower than the total number of potential candidates.

There has been a number of new issues for the Institutions due to the expansion of the higher education system, namely the large (sometimes vast) number of entering students and the gradual change in the nature of education provided. These changes have created new challenges for the Institutions, which need to adapt to new conditions, affecting among others the nature of teaching and learning.
By use of an empirical case study, this paper addresses the effect that online teaching may have on the evolution and improvement of education provided.

Throughout this paper, the term "higher education" refers to University/College systems, with students entering in general after graduation from highscool.

\section{GREEK Higher EdUCATION SYSTEM: NEW CONDITIONS AND RELATED CHALLENGES}

\section{A. Expansion and consequences}

For the past six decades, the greek higher education system is exclusively provided and financially supported by the state government. This state-run nature of the higher education is explicitly reflected on the Greek Constitution, preventing private organizations from providing similar states and degrees. This fact proves beneficial to students in several aspects, while creating certain problems in other aspects. The direct cost of study for the student is minimal (no tuition fees, textbooks provided by the system) and access to the system is equally guaranteed to all potential applicants, thus rendering family socioeconomic status rather unimportant in educational achievement. Lots of relevant work may be found in the literature (for example, see [1-4]). On the other hand, lots of pressure is put on the government by the society to constantly increase the number of available openings for students, thus creating an ever increasing financial burden, and making the education environment more and more difficult to handle, due to excessive number of students (the available positions are also determined by the government, usually far exceeding the figures asked for by the Institutions).

Traditionally, higher education has been highly regarded in Greece, as a means for professional and social advancement. During the 90s, a rapid expansion of higher education institutions throughout Greece was made possible by financial support from the European Union. Along with the continuous pressure by the society and the evolution of the economy toward a service economy, the financial support by the European Union provided the grounds on which a new active government policy was established to rapidly and extensively increase the percentage of students continuing into higher education.

The most immediate result of the aforementioned developments was the explosion in first-year places, leading Institutions in a situation they could not control. The total number of the places increased from approximately 10000 in the mid 80 s and 20000 in the early 90 s to over 80000 in 
the early 2000s, a figure that is almost equal to the number of highschool graduates.

\section{B. Changes in economy bring changes in education}

The vast majority of students come from the national public secondary school system, after passing through a countrywide examination. This system is widely viewed as examination-oriented, where students are not encouraged to think but only to memorize. The focus is mostly on lower, convergent cognitive levels of Bloom's taxonomy of educational objectives [5], whereas the analysis and synthesis levels are underdeveloped.

Due to the fact that it is almost certain that a student will enroll in a higher education Institution (either a University or a TEI), several Departments are faced with the reality that a substantial part of their first-year students possess very low qualifications. Combined with the fact that in some cases the number of students assigned by the government is very big (indicatively, the authors' Department accepts 420 students per year, whereas there are a few Departments accepting as many as 600 students), education quality is greatly affected. Typical lectures may become impossible to carry on, while students who possess sub-standard qualifications may never become interested in their studies. In addition, lots of students coming from lower-income families have to work to support their studies, while those coming from nearby areas who cannot afford to stay at the location of studies prefer to commute daily. These problems apparently make dropout even more likely for these students.

On the other hand, the Recommendation for the European Qualification Framework introduced by the European Parliament and the Council (Recommendation 2008/C $111 / 0,[6])$ moves the focus of higher education towards acquiring specific professional qualifications rather than general scientific knowledge, thus affecting the directions of the curricula of the Institutions.

In summary, based on the above analysis, one may identify several important characteristics of the current higher education environment in Greece:

- Rapid increase in the number of students entering the system

- Students with lower qualifications and less dedication to further studies

- Certain difficulties in achieving educational goals due to worse conditions

- Shift of focus in higher education goals throughout Europe

It is very important to note that similar remarks have been made by several researchers from completely different environments, such as England, USA and Hong Kong [7-10]. This observation leads the authors to believe that the transformations are led by the global socioeconomic changes rather than specific peculiarities in any given country.

\section{Online teaching and learning: how can it help?}

Given the changing circumstances outlined above, the question is what the Institutions can do to try to improve the situation and maintain their leading role in production of new knowledge, while keeping a satisfactory level of teaching. One of the new tools available to the educational process is e-learning. It gives to instructors the possibility to provide part of their classes through new software tools without classroom contact with the students. When combined to traditional forms of classroom teaching, blended learning is materialized. Extensive research work has been done in this area, arguing on the possibilities blended learning offers, e.g. $[11,12]$. In particular, it can help students organize their own time and pace, while encouraging them to interact with friends and classmates.

This study intends to explore the relationship between the students' level of awareness prior to entering an online class and their respective level of participation to the class, as well as the effect of the e-learning part of the course to their final performance.

\section{METHODS}

This research was run for two consecutive semesters, i.e. Spring 09-10 and Fall 10-11. There were 211 students enrolled in the course, however, only 164 followed the course till the end, fulfilling the requirements.

\section{A. The course environment}

For the past two years, the authors have been teaching the "Technical Writing" course, in a Department of Informatics technology. Upon successful completion of the course, the students should be able to write a full technical document (research paper, review essay, technical report) and create a visual presentation of the document. The participants were randomly divided into two groups for their face to face meetings but participated in the same class while using the LMS. The randomness of the two groups is confirmed by the final grade distribution (Fig. 1).

One has to take into account that minimal (if any) work has been done at the previous level and that students have practically no experience in literature search and in synthesis of various sources. The students are required to upload all deliverables in the course electronic space, but the main intention of the online component of the course is to allow students to seek interaction with the instructors at their own pace and encourage them to interact with other classmates. The course features a forum for asynchronous communication and a chat room for synchronous communication. The teacher's role in the online discussions is facilitative and there is always a commitment that one instructor will respond to any question or comment within 24 hours. In general, there is no real need for a tutorial, since the students are in the computers field of study, therefore there is enough familiarity with similar environments. The typical enrollment per semester is $100-120$

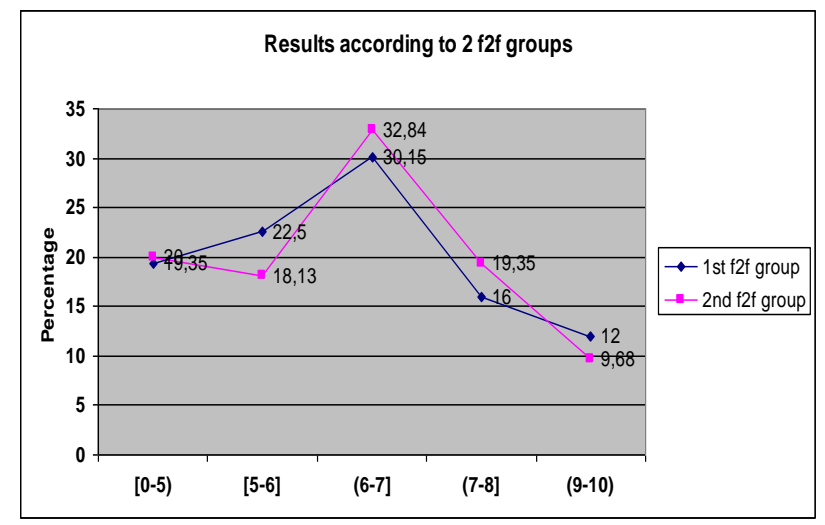

Figure 1. Final grade distribution for the 2 groups 
students. Material made available contains informative content (paper guidelines, library search possibilities), full examples of working papers and presentations, information sources and any other material that may prove useful to students.

\section{B. Surveys}

Students are requested to answer a survey at the beginning and near the end of the course. Most questions are constructed in Likert form [13], since it is convenient to evaluate either quantitative data or acceptance rate data. Both surveys contain an open-ended section, allowing students to express their expectations from the course at the beginning and their suggestions for improvement at the end. The surveys are anonymous to insure confidentiality, whereas an identifiable number (last digits of mobile phone or ID card) is included to allow for matching of the initial and final surveys.

\section{RESULTS}

\section{A. Flexibility in teaching}

One of the most important benefits of an online course environment is the ability to overcome time/place constraints on teaching. The course is available to everybody, even non-students, and there is no requirement to attend a class at a fixed day and time.

The students tend to prefer the synchronous online communication over the asynchronous at the beginning of the course. However, the asynchronous communication prevails in the post survey results (Fig. 2). This seems natural, especially for students who are familiar with the technology and use it for casual purposes as well. Synchronous communication looks attractive and alive; however, it resembles a traditional class, since one has to "attend" at specific days and times. On the other hand, the asynchronous communication creates a feeling that a response will certainly "be there" at a later time (in this case, one day at most).

A convenient feature of typical e-learning systems is the ability to track the characteristics of user access to the system. The statistics of the users support the flexibility consideration, since most of the connections to the LMS are made in the evening or even after midnight (Fig. 3). Again, the benefits of flexibility are underlined by this result. The preference for asynchronous communicaton is further confirmed by the fact that the students who work in parallel with their studies strongly prefer this form, for apparent reasons.

Finally, several students noticed in the post survey that this format of teaching provides several advantages over a traditional classroom meeting, namely unforced pace of presentation (reading rather than listening), ability to review content at a later point and ability to see the full context.

\section{B. Cooperation}

The cooperation among students was enhanced by the participation to the LMS. A high percentage of students answered that the ability to cooperate with other colleagues was substantially increased after completion of the course (Fig. 4). On the average, a score of 7,14 was recorded $(0=$ most negative change of ability, $5=$ no change, $10=$ most positive change in ability) .

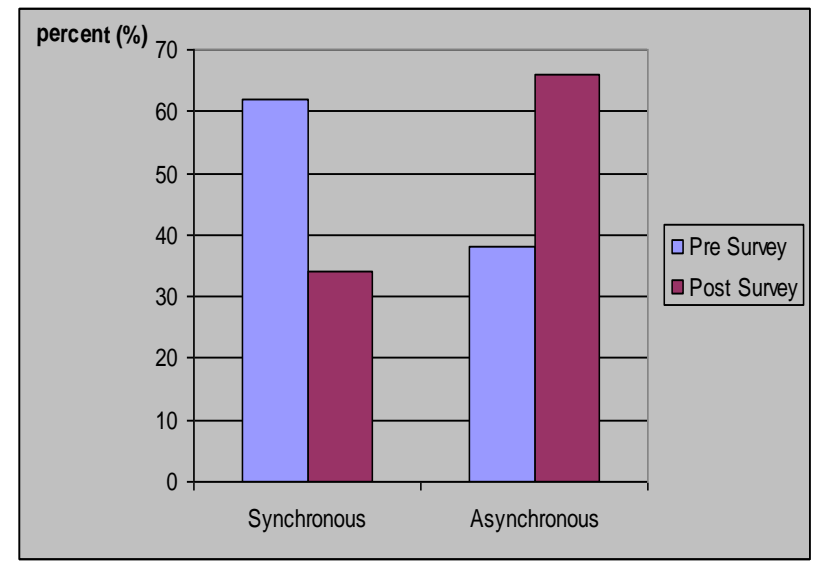

Figure 2. Preference of students for synchronous or asynchronous communication

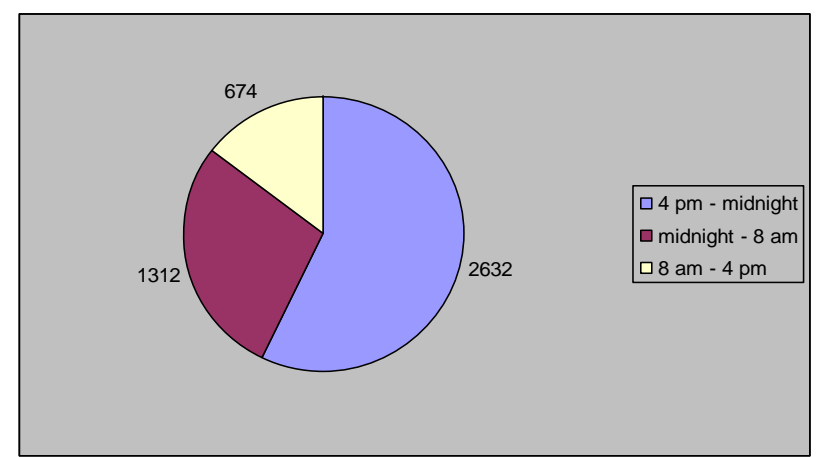

Figure 3. Statistics of student access to the LMS

This remark is made in most relevant research efforts, e.g. $[14,15]$. It is encouraging to notice that an environment that is not yet typical for a University promotes cooperation and improves the abilities of the participants.

\section{Awareness}

The students in the course typically have a moderate general familiarity with computers and social networks; however, their experience with e-learning systems is considered low. To try to get an estimate for the effect of this level of awareness, they were asked about the level of their prior experience in some LMS system. $36 \%$ had a prior experience, while $64 \%$ had no such experience. The students were then asked whether they thought their participation in e-learning improved their ability to cooperate with other coleagues (on a scale 0-100). Those with no prior experience had a substantially higher degree of improvement over those with some prior experience, as shown in Fig. 5.

The above observation may well be attributed to the fact that the absence of prior experience introduces those students to an entirely new field, of which they tend to make to most of. On the other hand, students with prior experience have already acquired similar skills in earlier phases of their student life; consequently, they do not exhibit similar improvement.

A further observation on the awareness and the participation of students given the level of their prior experience: the majority of the inexperienced students $(78 \%)$ made at most two active moves per week for participation throughout the course. They made use of the possibilities 


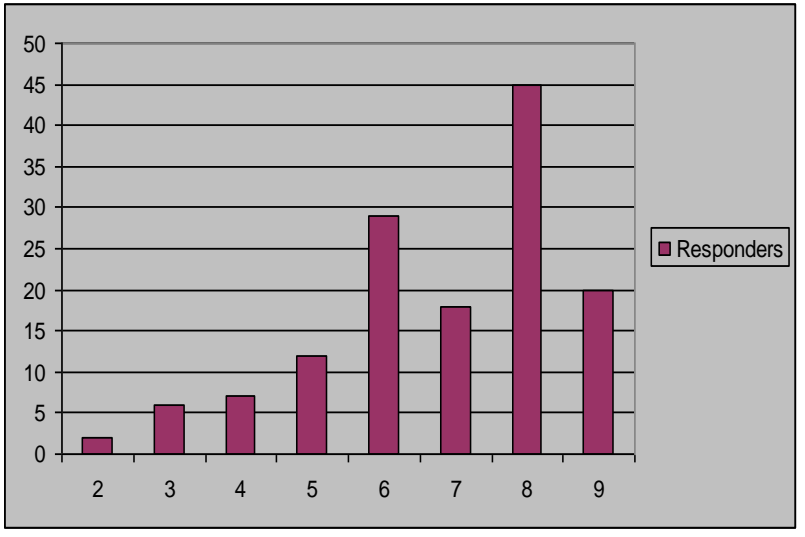

Figure 4. Improvement of cooperation ability (scale 1-10)

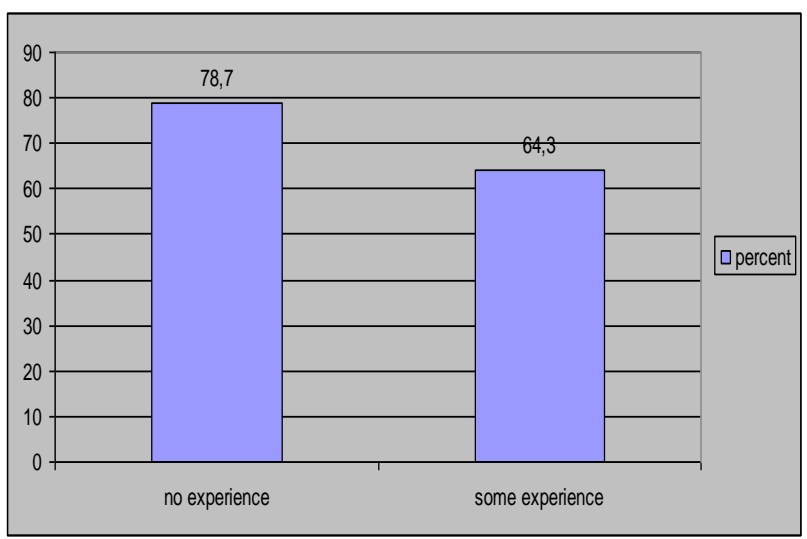

Figure 5. Degree of improvement based on prior experience to LMS

offered by the LMS (download most available files, frequent visits, etc.), however, they exhibited minimal activity in chats. The corresponding figure for the students with prior experience was $37 \%$. These figures may characterize the majority of the inexperienced students as "lurkers" $[14,15]$, i.e. individuals who prefer to watch rather than participate. This fact is not necessarily disappointing. In [16], an argument is presented that lurkers improve their learning from this procedure and this effect is beneficial to the community they are part of. A case study that confirms this argument is presented in [14].

\section{Improvement factors}

Students were asked whether their participation to the LMS had any effect on their feeling that they may find common interests with other students. Most students answered that there was a substantial improvement (average of 8,24 on a scale $0-10$ ).

Students were asked about the benefit from the possibility of cooperation with other students whom they don't know. Most answers indicated a positive opinion, although not in a strong way (average of 6,47 on a scale 0 $10)$.

Students were asked whether the level of their selfconfidence regarding the incorporation of new techniques and tools in their work has improved after the course. Most students answered that there was a substantial improvement (average of 8,56 on a scale $0-10$ ).

These results are tabulated in Table 1 partitioned for students with no prior experience and with some prior experience.
TABLE I.

IMPROVEMENT FACTORS RELATED TO PRIOR EXPERIENCE

\begin{tabular}{|l|l|l|}
\hline & \multicolumn{1}{|c|}{$\begin{array}{c}\text { No prior experi- } \\
\text { ence }\end{array}$} & $\begin{array}{c}\text { Some prior } \\
\text { experience }\end{array}$ \\
\hline Common interest & 8,18 & 8,36 \\
\hline Benefit from cooperation & 6,7 & 6,24 \\
\hline Self-confidence & 9,12 & 7,65 \\
\hline
\end{tabular}

As argued earlier, students with no experience tend to try to benefit from the technology, as is indicated by the last two sets of figures. One has to look at these numbers in perspective, since experience naturally implies a higher level to begin with, therefore margin for improvement is by default smaller.

\section{E. Success rate}

Success rate does not appear to be affected by the awareness or the active participation in the course. In fact, most students that follow the course and submit the deliverables required pass the course, without significant problems. It seems that the effect of participation and cooperation on success rate is difficult to measure using simple statistics and a more detailed method has to be applied. This is subject of future research already under way.

\section{DISCUSSION}

The empirical evidence provided above may be coded along the following lines:

- Students think that flexibility in teaching is important and helps their performance. This is in line with the current tendencies in the use of technology for social interaction and work. The students normally project these habits on their studies and may respond in a better way to alternative methods. Universities should take this development seriously into account in designing their policies and respond by encouraging their staff to follow this trend.

- Providing the students with new tools may prove very beneficial in stimulating new interest. This fact, combined with certain characteristics of higher education in Greece, may prove vital for the future of higher education Institutions. The Universities and Institutions that make good strategic moves can be better positioned to adapt in the new conditions.

- Cooperation among students is enhanced by elearning tools. It is indicated that students with little or no familiarity to the technology may become enthusiastic and try to benefit the most. Even minimal, "lurking" activity advances the sense of a community and produces learning results. Instructors should be willing to explore these possibilities and encourage these students to come forward.

- There was no significant difference of achievement among students with or without prior learning management experience. In terms of satisfaction though, students with less prior experience were more satisfied with the LMS's tools providing interactivity. We find comparable results in equivalent pilot studies [17]. Implications of these findings and recommendations for further study are under way.

In summary, there are good indications (which have to be further quantified) that the use of blended learning may strongly help in creating alternative stimuli for students, 
especially in the tranforming status of today's higher education

\section{SUMMARY AND FUTURE WORK}

During the last decade, e-learning tools and applications have made a strong entrance in the education field. Combined with the rapid expansion of higher education throughout the world and the strengthening of the concept of "lifelong learning", e-learning is becoming a powerful instrument to support traditional teaching, which can provide new improved possibilities. In Greece, most higher education Institutions have been moving towards this direction, in trying to cope with increased numbers of students and to stimulate interest in the studies.

This case study presented here has yielded encouraging results. The Department and more generally the TEI of Epirus may greatly benefit form incorporating the new technologies in its educational process. Of course, any institutional policy for online learning development should be in line with the goals and mission of the Institution. On the other hand, for any such policy to succeed, every Department should be willing to accept the developments and work towards their improvement.

Future research will focus on an effort to identify the effect of e-learning to overall student performance. Additionally, the problem of high dropout rates will be examined, trying to identify ways to stimulate interest in studies by use of alternative study methods, such as blended learning. Institutions moving in similar directions may be able to achieve "competitive advantage" over other Institutions, in an extremely competitive environment.

\section{REFERENCES}

[1] P. Tsakloglou and M. Antoninis "On the distributional impact of public education: evidence from Greece", Economics of Education Review, Vol. 18, Issue 4, October 1999, pp. 439-452

[2] M. Antoninis and P. Tsakloglou "Who Benefits from Public Education in Greece? Evidence and Policy Implications", Education Economics, Vol. 9, Issue 2, 2001, pp. $197-222$

[3] S. Kyvik "Structural changes in higher education systems in Western Europe", Higher Education in Europe, Vol. 29, Issue 3, 2004, pp. 393 - 409

[4] J. Katsillis "Cultural capital, student achievement, and educational reproduction: The case of Greece", American Sociological Review, Vol. 50, 1990, pp. 270-279

[5] B.S. Bloom, M.B. Englehart, E.J. Furst, W.H. Hill, and D.R. Krathwohl, Taxonomy of Educational Objectives: The Classification of Educational Goals. Handbook I: The Cognitive Domain, New York: Longman, 1956

[6] Official Journal of the European Union, 6/5/2008, http://eurlex.europa.eu/LexUriServ/LexUriServ.do?uri=OJ:C:2008:111:000 1:0007:EN:PDF
[7] K.M. Cheng, A.Y. Lai, C.C. Lam, K.S. Leung, H.S. Tsoi, POSTE: Preparation of students for tertiary education: Final report: A study commissioned by the University Grants Committee, 4th Ed., Hong Kong, Hong Kong Government Printer, 1996

[8] M.R. Lea, B.V. Street, "Student writing in higher education: An academic literacies approach", Studies in Higher Education, Vol. 23, Issue 2, 1998, pp. 157 - 172. http://dx.doi.org/10.1080/03075 079812331380364

[9] L. Thomas "Student retention in higher education: the role of institutional habitus", Journal of Education Policy, Vol 17, Issue 4, 2002, pp. $423-442$

[10] E. Schofer, J.W. Meyer "The Worldwide Expansion of Higher Education in the Twentieth Century", American Sociological Review, Vol. 70, No. 6, December 2005, pp. 898-920. http://dx.doi.org/10.1177/000312240507000602

[11] D.R. Garrison, H. Kanuka, H. "Blended learning: Uncovering its transformative potential in higher education", The Internet and Higher Education, 7, 2004, pp. 95-105. http://dx.doi.org/ $\underline{10.1016 / \text { j.iheduc.2004.02.001 }}$

[12] M.J. Rosenberg, E-Learning: Strategies for delivering knowledge in the digital age, McGraw-Hill, New York, USA, 2001

[13] W. Trochim, The Research Methods Knowledge Base, 2nd Ed., Atomic Dog Publishing, Cincinnati, OH, 2000.

[14] A. Tomsic and D. D. Suthers, "Discussion Tool Effects on Collaborative Learning and Social Network Structure", Educational Technology \& Society, 9 (4), 2006, pp. 63-77

[15] M. Vivitsou, N. Lambropoulos, D. Konetas, M. Paraskevas, E. Grigoropoulos "The Project Method e-course: the use of tools towards the evolution of the Greek teachers' online community", International Journal of Continuing Engineering Education and Lifelong Learning, Vol. 18, 1, 2008, pp. 26-39. http://dx.doi.org/10.1504/IJCEELL.2008.016074

[16] E. Wenger, R. McDermott, R. Snyder, Cultivating Communities of Practice: a Guide to Managing Knowledge, Harvard Business School Press, Boston, 2002.

[17] H.-J. Lee, I. Rha, I., "Influence of Structure and Interaction on Student Achievement and Satisfaction in Web-Based Distance Learning", Educational Technology \& Society, 12 (4), 2009, pp. $372-382$.

\section{AUTHORS}

Nikolaos Antoniadis is a professor at the Department of Informatics and Telecommuncations Technology, TEI of Epirus, Arta, GR47100 Greece. He has a Ph.D. in Electrical Engineering from the University of Michigan. (email: nadon@teiep.gr).

Dimitrios Konetas is a part-time lecturer at the Department of Informatics and Telecommuncations Technology, TEI of Epirus, Arta, GR47100 Greece. He holds a teacher position for Informatics and New Technologies at a highschool in Ioannina, Greece. (dkonetas@teiep.gr).

This article is an extended version of a presentation at ICELW 2011 The International Conference on E-learning in the Workplace, held from June 8th-10th, 2011 at Columbia University, New York, NY, USA. Manuscript received 4 July 2011. Published as submitted by the authors August $5^{\text {th }}, 2011$. 